\title{
A tradução de E.E. Cummings na formação de um cânone doméstico/brasileiro: um estudo de caso sobre projeto tradutório de Augusto de Campos
}

\author{
Juliana Cristina Salvadori* \\ Universidade do Estado da Bahia \\ Salvador, BA, BR \\ Mônica Santos Silva \\ Universidade do Estado da Bahia \\ Salvador, BA, BR
}

\begin{abstract}
Resumo
Este trabalho concentra-se nas traduções da obra de E. E. Cummings levadas a cabo da década de 1960 até os anos 2010 pelo poeta-tradutor-crítico Augusto de Campos, destacando como esse longo projeto tradutório, desdobrado em 5 edições (10 poemas, 20 poem $(a) s, 40$ poem $(a) s$ e duas edições de Poem $(a) s$ ), se coaduna com a proposta crítica e pedagógica do movimento de poesia concreta de formar um paideuma de autores referência que norteasse a produção e a recepção de uma nova poiesis voltada para a técnica. Para tanto, as escolhas tradutórias do poeta-tradutor privilegiam, como ele mesmo destaca, o que há de mais inovador na obra do poeta (sua tortografia), seus aspectos formais, obliterando o eixo lírico-amoroso dominante na obra e construindo um cânone doméstico/brasileiro distinto.
\end{abstract}

Palavras-chave: E. E. Cummings; Augusto de Campos; Poiesis; Tradução; Crítica

\section{The translation of Cummings' work and the constructon of a domestic/Brazilian canon: a case study regarding Augusto de Campos's translation project}

\begin{abstract}
This work focuses on the translations of Cummings' work made by Brazilian poet, critic and translator Augusto de Campos between the 1960s and the 2010s, highlighting how this long-term project (comprehending 5 editions, namely 10 poemas, 20 poem (a)s, 40 poem(a)s and two versions of Poem(a)s) grounds the critical and pedagogical proposal of the concrete poetry movement. The movement aimed at building a paideuma of writers focused on an innovative technique to teach both writers and readers this new poiesis. The translation choices made by Augusto de Campos, thus, privilege, as he acknowledges, Cummings's most innovative traits (and poems), that is, the formal aspects, obliterating the lyrical aspects of Cummings and building a domestic/ Brazilian canon for Cummings.
\end{abstract}

Key words: E. E. Cummings; Augusto de Campos; Poiesis; Translation; Criticism

\footnotetext{
* Juliana Cristina Salvadori é Professora Assistente da Universidade do Estado da Bahia (UNEB) no Curso de Letras Língua Inglesa e Literaturas, no qual, dentre outras atividades, coordena o grupo de Pesquisa Desleituras em série: da tradução como transcriação, adaptação, refração, diáspora (http://dgp.cnpq.br/dgp/ espelhogrupo/1792517921828602). Suas principais áreas de atuação e interesse são teoria e crítica literária, leitura e formação de leitores, tradução como leituraescritura. Email: jsalvadori@uneb.br

** Mônica Santos Silva é graduada em Lingua Inglesa pela Universidade do Estado da Bahia - UNEB. Formou-se em 2012 ao defender a tese de conclusão de curso intitulada "Entre e.e Cummings e Augusto de Campos: Análise da Tradução de Fragmentos de Poemas de e.e. cummings a Partir dos Pressupostos teóricos da Transcriação e da Poesia Concreta”, na qual analisa a tradução da poesia cummingsiana de acordo com um novo modelo de tradução. E-mail: ssantoss.monica@ gmail.com
} 
Uma das questões que mais nos intriga sobre o poeta estadunidense E. E. Cummings, considerado um poeta menor, é a divergente recepção crítica que sua obra suscitou, durante os cerca de 40 anos em que foi publicada, de meados dos anos 1920 até a década de 1960, passando o autor, no contexto da recepção crítica americana, de avant-garde (em um primeiro momento, devido à sua excêntrica pontuação e tipografia) à romântico-tardio-decadente (crítica advinda principalmente do New Criticism a partir da década de 1930 em diante) à modernista - qualidade reconhecida pelos seus pares, como E. Pound, por exemplo. Esta questão se torna ainda mais intrigante pelo fato de os novos críticos, ${ }^{1}$ repetidamente apontarem que a obra poética de Cummings "não evoluía", isto é, que o poeta trabalhava com as mesmas técnicas - como as espacio-tipográficas, por exemplo, inicialmente louvadas, mas posteriormente consideradas idiossincrasias e mesmo sinais de sua imaturidade - e temas. Este artigo, contudo, não se concentrará na recepção do autor em contexto americano, mas sim brasileiro, com o propósito mostrar como a questão da crítica se imbrica ao processo de leitura/ interpretação da obra do autor em contexto estrangeiro, contribuindo para formar, por meio da tradução, o que Venutti (2002) denomina de cânone doméstico de um autor estrangeiro que acaba por contemplar pautas locais (neste caso, o projeto de pedagógico-crítico-literário do movimento de poesia concreta). Em outras palavras, no caso do contexto brasileiro, a circulação e recepção da obra de um poeta estrangeiro "menor" como Cummings - com várias das implicações que tal termo pode suscitar - passa pela questão da tradução: o projeto concretista de tradução, e, neste, o projeto tradutório de Augusto de Campos sobre a obra de Cummings merece destaque na formação deste cânone doméstico/ brasileiro de Cummings, iluminando a leitura da obra cummingsiana a partir dos aspectos técnico-formais, conquanto que obscurecendo outros aspectos sobre sua obra, como a vertente lírico-amorosa, mais tradicional.

O menor pode ser (re)interpretado pela noção de literatura menor de Deleuze e Guattari (1977) - que tomam tal denominação pejorativa e a subvertem em seu ensaio Kafka: por uma literatura menor. Segundo os autores, literatura menor é "[a literatura] que uma minoria faz em uma língua maior" (1977, p.25). Nessa perspectiva, por sua técnica de implodir a linguagem via tmese, ${ }^{2}$ pensamos Cummings, de fato, como um poeta menor: talvez porque ser poeta seja sempre trabalhar de modo a subverter uma língua maior - essa do dia-a-dia, automatizada. Nosso poeta trabalha a partir da sua língua, isto é, "de dentro", estilhaçando-a - sintaxe, ortografia e verso - e abrindo espaço para o outro, no caso, para essa tradição latina de certo modo deslocada em um mundo anglo-saxão no qual as referências clássicas, embora desejáveis, tornam-se objeto de veneração - totem - insígnias de poder mais que fontes vivificantes, potencialmente restauradoras ou inovadoras para/de uma tradição poético-literária.

Por outro lado, não podemos nos esquecer que Cummings é também chamado, carinhosa e desdenhosamente, de poetinha, de poeta menor, o poeta que se subscreve "e. e. cummings", o poeta das minúsculas - das letras minúsculas; do pequeno, minúsculo "i” (eu), das minúsculas cenas do cotidiano; dos minúsculos detalhes; das minúcias tipográficas e vocabulares, em oposição ao normativo, egóico, “I”. Não há espaço para a prolixidade e para o grandioso em sua poiesis, pois não há mais lugar para o tom heróico-épico nesse mundo em que temos, apenas, pequenos e fragmentados “i”. Não há espaço para essa falácia desse unívoco, maiúsculo, "I" no mundo de Cummings, pois, afinal, esse "small i/eye" traz o jogo duplo e ambíguo: o olhar do poeta é o do detalhe, das pequenas coisas, esse olho pequeno, ou melhor, esse olhar o pequeno.

Esse "menor" figura, também, na escolha do poeta em trabalhar com o essencial da linguagem justamente a partir do tido como não essencial sintaticamente, isto é, a partir dos termos acessórios e não dos ditos de "conteúdo". Como diz Lionel Trilling, citado por Augusto de Campos (2011, p. 14), a respeito do poeta:

Ele foi capaz de encontrar mais e mais vida em mais e mais palavras. Aquelas partes da linguagem que todos considerávamos apenas 'modificadoras', 'relativas' ou 'dependentes' aprenderam com ele a ter uma existência plena e livre. É esse o caso de prefixos como "un-", ou "non-", ou sufixos como "-less", "-ness" ou "-ly", que se unem a outros vocábulos para criar novas 
palavras, por exemplo: "nonsun" (nãosol) ou "sunly" (solmente) ou "dreamlessnesses (semsonhidades). E de partículas como "a", "un", "self”, “much”, “when", “if”, “am”, convertidas em substantivos.

Augusto de Campos, contudo, não dá seguimento, em seu ensaio, à análise dessa escolha do poeta pelo menor, do tido pelo consenso como acessório, como não-essencial na oração, isto é, dessa sistemática negação empreendida pelo poeta sobre o "o quê" e o "como" da poesia, que se expressa, inclusive, por meio das partículas e afixos escolhidos e preferidos por Cummings: “un-", “non-”, “-less”. O não (“un-”, “non-”), a falta (“less"), o abstrato (“-ness") concretizado pela falta no significante: dreamlessnesses. O poeta, portanto, por meio desse léxico e sintaxe cindidos e ressignificados, subverte a ordem espácio-temporal não somente da poesia mas também da linguagem propondo, por meio de sua ex-cêntrica tipografia, a descentralização e, logo, a disseminação, da palavra, do significante, e, logo, do sentido: uma opção pela desorientação, pelo se perder na página, na letra do texto. O tradutor-poeta Augusto de Campos escolhe a dedo - e olho - textos e trechos da obra poética de Cummings que melhor destacam essa técnica/ techne cummingsiana do estilhaçamento do poema (verso, linha, palavra), iluminando-a por meio de sua tradução, desdobramento crítico e criativo das obras dos poetas, ambos, tradutor e traduzido.

Em outras palavras, a opção por Cummings, nossa e dos poetas concretos, mais especificamente de Augusto de Campos em meio à consciente gestação de um paideuma, ${ }^{3}$ diz da escolha por essa atração pelo menor, figurada pelo foco na técnica minuciosa. Essa técnica, em Cummings, é visivelmente exercida sobre o menor, sobre as próprias palavras, tomadas como matéria-prima a serem decompostas e recompostas para se criar (outros) efeitos de significado, cindidas de modo a lhes reestabelecer a potencialidade, em sua raiz, que os afixos comuns acabam por limitar/obscurecer. Essa "tortografia” (2011, p. 25) segundo Augusto de Campos,

tem em mira efeitos construtivos de sinestesia do movimento e fisiognomia descritiva. Sob a aparência epidérmica de idiossincrasia e anar- quismo, a tortografia cummingsiana é, paradoxalmente, a correção de uma ortografia inane para a poesia, de uma mortografia, ao mesmo tempo que uma das mais sérias tentativas de fazer funcionar dinamicamente o instrumento verbal, reduzindo a um mínimo - como nota Theodore Spencer - a distância entre experiência e expressão. (2011, p. 25)

O poeta menor o é, também, por tentar trabalhar no menor espaço possível entre experiência e expressão, exíguo espaço que se dá entre o deslizamento de significante a significante. Cummings, por meio de sua tortografia, como bem aponta Campos (2011), consegue espacializar essa experiência do movimento. Aliás, o próprio Cummings já deixa claro como essa dimensão da experiência lhe norteia a escrita em sua introdução ${ }^{4}$ a São 5 (IS 5), ${ }^{5}$ livro de poemas originalmente publicado em 1926. Essa introdução, não coincidentemente, é o primeiro texto a abrir Poem $(a) s$, edição revista e ampliada de 2011, que retoma a anterior (1999), concebida para reunir todas as traduções efetuadas por Campos da obra de Cummings de modo a cobrir as várias fases e publicações do poeta estadunidense.

"Como o comediante burlesco, sou extraordinariamente apegado àquela precisão que cria o movimento", assim Cummings inicia a introdução de IS 5. Esse movimento é emulado, em parte, pela criadora atomização das palavras, referida por Campos como "o delicado artesanato do poeta” (2011, p. 34), em artigo originalmente publicado como prefácio à segunda edição de sua empreitada tradutória de Cummings, E. E. Cummings 20 poem(a)s (1979). Delicado, aliás, é um adjetivo relativamente estranho quando usado para qualificar a técnica cummingsiana e merece ser mais bem analisado. É, de fato, da perspectiva de poeta-tradutor que Campos interpreta a técnica de Cummings, isto é, a partir da tradução desafiante/desafiadora que demanda atenção para o significante, para o material da poesia, para o menor. A princípio, a presença de Cummings em meio à heterogênea paideuma selecionada pelo movimento de poesia concreta via crítica e tradução causa espanto: afinal, Pound, Cummings e Joyce não “conversam” em suas propostas e projetos literários. Há que se apontar, inclusive, o que o próprio Cummings deixa claro na "introdução", acima citada, de IS 5: a teorização sobre 
um projeto maior para a literatura não está contemplada em sua prática. A "introdução" apresenta-nos sua poesia como "pura" poiesis, voltada para/a si mesma, recusa da circunscrição/contenção no campo textual, movimento para a/a partir da realidade circundante. Em um segundo momento, a partir da perspectiva do poeta-tradutor, a opção de Campos por Cummings nos diz algo sobre sua proposta crítico-literária-pedagógica que acaba por trazer ao leitor brasileiro apenas um dos aspectos da obra de Cummings, sua técnica inovadora, pautado pela agenda do movimento de poesia concreta que partia de um conceito de poiesis que toma o poema como signo e ícone em seu aspecto verbi-voco-visual.

Para pensar essa tradução de Cummings no Brasil estudaremos a segunda edição do livro $\operatorname{Poem}(a)$ s: e. e. cummings (2011). Vimos argumentando ao longo do texto que Augusto de Campos - poeta, ensaísta e tradutor - condensaria em sua empreitada tradutória a poiesis concretista na qual a dimensão do fazer - techné - do craft/arte conflui e rompe as distinções entre gêneros literários: a crítica, o poema, a tradução, iniciando, junto a seu irmão Haroldo de Campos, tradição tradutória que tem como mérito pensar o papel do tradutor e negar sua invisibilidade justamente por colocar em pauta o horizonte do tradutor, uma confluência de sua posição tradutória e de seu projeto de tradução, conceito tomado de empréstimo à teoria da recepção não por acaso: afinal, o tradutor é a convergência entre autor e leitor, se não do leitor ideal, do paranóico, que ilumina aquele outro texto, o dito original. Essa dimensão de craft/artesanato, de téchne, do fazer, é realçada na década de 1980 pela chamada Poética da tradução que tem em A. Berman e em H. Meschonnic seus dois nomes mais representativos. Nessa perspectiva, a tradução é encarada a partir de seu fazer - a tradução não é um dizer, mas um fazer, diz Meschonnic (2009); uma experiência-reflexão, nomeia Berman (2007).

Em Poem (a)s, publicado pela primeira vez em 1999, Augusto de Campos reuniu 74 poemas extraídos de diversas obras de Cummings, além de diversos ensaios sobre o autor, publicados nas edições anteriores de suas traduções (a saber, 10 poemas, 20 poem(a)s, 40 poem(a) s). Nesta versão de Poem $(a)$ s, segue-se o procedimento adotado nas edições anteriores: o poema original ocupa o lado esquerdo da página e sua tradução/transcriação o lado direito, isto é, estão lado a lado, conforme solicitado por Cummings desde os primeiros contatos com Augusto de Campos. Como as poesias não são tituladas - uma das marcas da poética cummingsiana - adota-se a convenção de tomar como título a primeira sentença de cada poema (opção interessante, mas nem sempre prática no caso de Cummings, que explode a palavra e o verso) e opta-se por numerar cada um dos poemas, em ordem crescente, totalizando 74 na segunda edição de Poem(a)s (2011).

As traduções das obras de Cummings por Augusto de Campos se iniciaram por volta de 1956, quando o brasileiro contatou o poeta, solicitando permissão para transcriá-lo para a língua portuguesa e a correspondência entre ambos é extensamente documentada - aliás, esse status de work in progress e o foco no artesanato/ craft de traduzir Cummings fazem parte e explicitam tanto o projeto tradutório quanto a posição tradutória de Campos. Desde o contato inicial entre os poetas e a publicação da primeira obra de Cummings traduzida para a língua portuguesa, E. E. Cummings - 10 poemas, levou-se quatro anos de trabalho árduo. Augusto de Campos, no prefácio dessa edição, afirma ter selecionado dez dentre os visualmente mais complexos poemas de Cummings, indo, segundo o mesmo, em direção inversa aos tradutores de Cummings para outras línguas, como para o espanhol. ${ }^{6}$ É pertinente observar como essa primeira empreitada tradutória se desdobrará em outras obras, tarefa/renúncia de uma vida: $E$. $E$. Cummings - 20 poem(a)s, depois E. E. Cummings - 40 poem (a)s e daí "só" E. E. Cummings - Poem(a)s (1999). De fato, esse processo de obra a se fazer, essa seleção que continuamente se amplia e desdobra, aponta-nos duas questões vitais: a primeira, obviamente, diz respeito ao papel designado pelos concretos (como preferem ser chamados, em oposição a concretistas) a Cummings, isto é, ao seu lugar no paideuma concretista, um lugar que se amplia talvez e justamente porque Cummings e sua poiesis dão lugar para que a poiesis concreta, particularmente via tradução, expanda-se em seus interstícios; a segunda diz respeito ao percurso e seleção dos poemas, conforme apontado pelo próprio $\mathrm{AC}$, em "E. E. Cummings, sempre jovem", ensaio-introdução apresentado na edição de 1999. 
Esse percurso de seleção e ampliação do repertório de tradução de Cummings para o público brasileiro é manifestamente interessado e integra uma estratégia ampla de formação de leitores. Parte-se, como o próprio Campos aponta em 10 poemas, do Cummings "mais revolucionário e o menos aceito e entendido", passa-se daí aos "humores e sutilezas" de sua obra (20 poem(a)s e 40 poem (a)s) para desembocar, finalmente, em todas as fases, inclusive a menos apreciada pelos concretos e pelo tradutor, as ditas "composições líricas da juventude como 'somewhere i have never travelled', exemplos de uma lírica discursiva em que nem o verso nem a palavra haviam sido implodidos mas nos quais a técnica cummingsiana de potencialização do sentido pelo significante também age. Podemos dizer que esse Cummings não interessa de saída porque tanto não desafia o tradutor quanto não era exemplar para o paideuma: interessa o Cummings mais revolucionário, e é preciso pensar nessa escolha e avaliá-la conforme as edições se sucedem, observando quais poemas são acrescidos e seu caráter de exemplar da técnica e temática cummingsianas.

Foi a ex-centricidade da crítica empreendida pelos poetas concretos, particularmente por Augusto de Campos, quanto à obra cummingsiana - ex-cêntrica porque fora de um centro geográfico-cultural-linguístico, ex-cêntrica porque desviante de um centro teórico -ideológico - que nos chamou a atenção, pela primeira vez, para o aspecto sistemático de sua empreitada tradutório-crítico-pedagógica. Nesta, a tradução, interpretada como transcriação, como trabalho crítico-revisionista e poético-literário, isto é, no quadro do projeto antropofágico que vê a leitura sempre e já como uma escrita, re-escrita, desempenha papel fundamental: essa outra lógica se instaura a partir da dimensão de poiesis que as três operações - traduzir, criar e criticar - performam na linguagem, via significante. É interessante perceber também como o vocabulário linguístico-teórico é transposto pelo autor de modo a aproximar essas realidades: traduzir é já ler e escrever de modo crítico, teoricamente informado.

A escolha pela obra de um poeta como Cummings, com sua desviante tessitura verbi-voco-visual, vai ao encontro do conceito de transposição criativa e, particularmente, do projeto e da visada tradutória de
Augusto de Campos: olho e fôlego. "E. E. Cummings: olho \& fôlego", aliás, é o título do ensaio-introdução que abre o primeiro livro de transcriações de Campos, 10 poemas. Nessa edição, o lugar de Cummings bem como suas filiações no paideuma de poesia concreta são bem demarcados: "ao lado de Pound e Joyce", "que mantém uma sadia atitude de inconformismo" a anunciar o "canto de cisne do 'verso"' (p. 23); da linhagem de Mallarmé visto que de um a outro "o caminho a percorrer é quase uma linha reta" (p. 24), poetas no qual "a grafia se faz função", Cummings, contudo, é visto como sucessor-predecessor da experimentação, exacerbando e exasperando-a. ${ }^{8}$

A tortografia cummingsiana, portanto, esse caráter artesanal de sua poesia que trabalha na litera, amplificando suas possibilidades de significação por meio do cindir das mesmas em pré e pós fixos, seria a característica base a nortear a escolha do poeta-tradutor. Por questões de natureza didática, apresentaremos nos seguintes parágrafos as edições das traduções de Cummings, feitas por Augusto de Campos, conforme sua data de publicação, partindo da perspectiva da tradução como uma das frentes em que o movimento de poesia concreta atua, juntamente à crítica e à poesia, para efetivação de seu projeto pedagógico-crítico-literário que almeja, em um primeiro momento, educar e mesmo criar um público letrado, literariamente letrado, nas convenções e técnicas das quais a poesia concreta se coloca como herdeira; em segundo, transgredir/transcriar os gêneros fazendo convergir o literário, o teórico e o crítico, optando por teorizar/criticar/refletir a/na/sobre a literatura, destacando a dimensão de poiesis, isto é, de fazer criativo que tais atividades encetam. $\mathrm{O}$ corolário dessa frente tradutória, como veremos pelo exame das edições, é a criação de um cânone doméstico para a obra de Cummings que privilegia os poemas em que a técnica cummingsiana está mais explicitamente em ação: basta um rápido exame com qualquer ferramenta de busca ou nas bibliotecas de dissertações e teses para perceber o enfoque dos trabalhos neste corpus traduzido e posto em circulação por Augusto de Campos, corpus reduzido se considerada tanto a amplitude de sua obra quanto a temática privilegiada - $\mathrm{o}$ amor, a natureza, cenas simples do cotidiano (vide Paz, 1976) . 
Da primeira edição de traduções de Cummings publicada por Augusto de Campos a partir de uma pequena amostra (10 poemas) cinco pertenciam ao livro No thanks (1935), seleção mais representativa da marcante tipografia poética cummingsiana. São esses $o$ pr (ó pr), $r$-p-o-p-h-e-s-a-g-r / o-h-o-t-n-a-f-g-a, go(perpe)go / vai(perpé)vai, birds( / aves( , brIght / brilha (respectivamente os poemas 4, 5, 6, 7 e 8 desta edição. Os demais 5 poemas são escolhidos a dedo, escolhas "exemplares" segundo o critério da inovação tipográfica: eu estarei, de $\triangleleft(A N D)$, segundo livro do poeta, publicado em 1925; MEMORABILIA, de IS 5 (1926); crep-úscu-Luz ave, de W (VIVA) (1931); e “(plu”, de XAIPE (1950). Na capa, a título de ilustração, um trecho do poema BrIght.

É preciso repensar BrIght no contexto da literatura de língua inglesa, no refazer de modelos poéticos estabelecidos, como o soneto. Abaixo, como aparece nas edições citadas, o poema em língua inglesa, à esquerda, e o texto-tradução, em língua portuguesa:

21
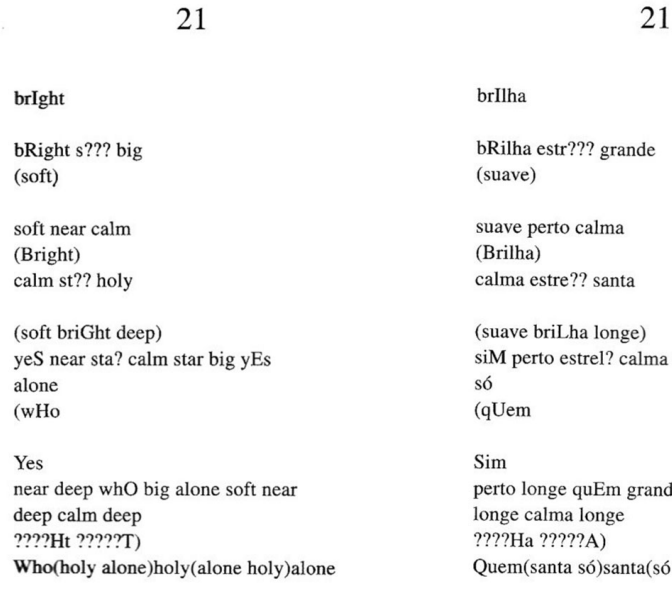

Figura 3: Poema 21: brIght CUMMINGS/CAMPOS, 2011, p. 98-99

Esse poema pode ser considerado um exemplo de ideograma no estilo cummingsiano - tanto o é, que o tradutor e editor o selecionam para figurar na capa. Diferente de Appollinaire, poeta francês criticado pelos concretistas por ceder à facilidade visual dos caligramas, Cummings segue um caminho menos óbvio. Observe que o poeta, na própria palavra "brIght" trabalha o núcleo gráfico do termo - I maiúsculo - como um meio de representar o brilho da palavra/coisa: a palavra é signo e ícone, pois, além de nomear, emula/encarna/é a coisa-em-si nomeada, o brilho intermitente daquilo do qual se diz, do substantivo ao qual os adjetivos qualificam (bright, soft, near, calm, holy) mas que é apenas entrevisto/sugerido na primeira e segunda estrofes (s???, st??) até que, finalmente, surge na terceira estrofe (sta?; star). Essa sua cintilação/oscilação é desenhada em caixa alta, inscrita no adjetivo que o qualifica intrinsecamente - bright. Ao longo do poema, a grafia varia, sempre uma das letras em caixa alta: brIght, bRight, Bright, briGht e depois o H e o T (????HT????T). Na tradução, segue-se o mesmo padrão: brilha, bRilha, Brilha, brilha, e depois o $\mathrm{H}$ e o A, maiúsculos, a apontar que, talvez, o brilho esteja a esmorecer (vem o dia?), pois a estrela, que apenas se entrevia, tornou-se nítida lá pelo meio do poema - star/near - próxima, calma, grande. Contudo, na tradução, o adjetivo sofre recategorização - de adjetivo passa a verbo: brilha, uma escolha graficamente feliz, visto que segue o esquema imagético (bright/brilha, seis letras, podendo ser cindidas e retrabalhadas, e mantendo similaridade nas iniciais - bri/bri, pelo menos na escrita, se não na pronúncia). Ademais, o "brilha", que inicia o poema, é a conjugação do verbo no imperativo e evoca, da memória sonora do leitor, a canção de ninar (brilha, brilha estrelinha), que o poema de Cummings retoma no último verso "Who(holy alone)holy(alone holy)alone". Este verso final evoca o verso da cantiga de ninar como cantado por uma criança: na repetição do verso, a consoante líquida - 1 - toma o lugar do "r", seja pelo sono, seja pela ininteligibilidade do verso para criança pequena: "How I wonder what you are. How I wonder what you are" . Uma compensação, então, se processa nessa troca do adjetivo bright pelo verbo brilha: a evocação da cantiga de ninar, pelo título do poema e pelo seu início, na versão brasileira, e não apenas no final do poema como o texto fonte em língua inglesa. Os demais adjetivos que predicam a estrela e a rede de sinonímias e antonímias que tecem também é recriada: em Cummings, a estrela é soft/suave, near/perto, calm/calma, holy/santa e, no final das contas, big/grande, como se, finalmente visível, em toda sua efulgência, até que, talvez pelo advento da aurora, pelo caminhar da noite, ela se torna deep/ distante (adjetivo repetido três vezes nos versos 11 e 12) 
e, além de distante, alone/só. O jogo rítmico-repetitivo à la trava-línguas do último verso, brincando com os sons de wh/h e do "l" ("Who(holy alone)holy(alone holy)alone") é transcriado na aliteração o "s" - (santa/ só) santa(só santa) só. Há a transcrição do jogo sonoro por meio da aliteração, mas perde-se o jogo de holy/ alone com whole: total ou completamente - a enfatizar a o aspecto solitário da estrela - só e sagrada.

$\mathrm{Na}$ cantiga de ninar, a estrela está tão distante, tão alta, tão pequena (há vários adjetivos, pelo menos um em cada verso, a enfatizar a pequenez da estrela, se não em seu tamanho, na magnitude de seu brilho: little star, little light, tiny spark) em comparação com o sol (blazing sun). No soneto cummingsiano, a estrela, de fato, só chega a se tornar nítida, luminosa, brilhante no oitavo verso desse soneto, se assim o podemos denominar, de 15 versos (a menos que consideremos o primeiro "brIght" apenas como título, o que nos daria as 14 linhas do soneto tradicional), isto é, no meio do poema e de sua trajetória pelo céu noturno. Depois, paulatinamente, apaga-se, do poema, não mais a estrela, mas sua luminescência - no décimo terceiro verso: (????HT????T). Percebemos, pelas escolhas, que Augusto de Campos, em acordo com seu projeto e posição tradutórios, não teve como objetivo tornar o texto mais acessível; ao contrário, reconstruiu a associação entre letras em caixa alta e momentos de cintilação/brilho no texto, evocando a memória auditiva da cantiga de ninar. ${ }^{9}$

A segunda edição das traduções da obra de Cummings feitas por AC, 20 poem (a)s, surge em 1979, pela Noa Noa: 600 cópias artesanal e amorosamente montadas pelo editor Cléber Teixeira, a quem Campos, em seu ensaio-prefácio "Não, obrigado", ${ }^{10}$ atribui o papel instigador. "Alguém nos ouvirá?", pergunta o tradutor, fundindo neste "nós" o autor, o tradutor e o editor. O próprio responde - não importa. A relevância da resposta, contudo, não reside no impacto desta quanto à empreitada - traduz-se e publica-se - mas na emulação daquele gesto da vanguarda, gesto de desdém para com o público e o establishment - literário, editorial, crítico. Dito de outro modo, ao "não,obrigado" só se pode responder com um "não importa": a resistência constitui-se, de fato, uma narrativa mais interessante. A resistência encontrada por Cummings para publicação de seus poemas é narrativizada por Augusto de Campos como mito de fundação, quest e destino partilhados tanto pelo tradutor quanto pelo editor e reforçam o papel de força desestabilizadora, não cooptada, da poiesis inovadora que, defende Campos, tem em sua "estrutura gráfico espacial (...) o elemento material, objetivo [afixação e montagem de palavras, número de letras e de linhas, deslocamento sintático, microrritmia], capaz de fornecer a chave de uma experiência que visa, acima de tudo, àquela precisão que cria o movimento' (...)". Fundamentalmente incompreendido pela crítica americana, principalmente por aqueles filiados à vertente da nova crítica que busca mensurar e interpretar a obra cummingsiana a partir de instrumentos e conceitos inapropriados - "eles não sabiam o que fazer com ele", cita Campos, incluindo no balaio Blackmur e T. S. Eliot - resta esperar que o autor seja melhor ou bem lido: é preciso, então, um projeto que desvele, epifanicamente, na materialidade do signo/ícone poético, sua obra. Nessa narrativa de cunho épico, entra em cena o movimento de poesia concreta brasileiro e seu pioneirismo:

E foi por tê-lo entendido mais cedo que os outros, que a poesia concreta brasileira - que já no início da década de 1950 situava Cummings na perspectiva das novas estruturas poéticas e da "obra aberta" - pôde estar presente e antecipar-se à "reabilitação" do poeta, que começou lenta e indecisamente nos próprios EUA, depois da publicação dos seus Poems 1923-1954. Mais ainda. O ritual do boicote e da ignorância em torno da poesia "tipográfica" de Cummings foi rompido, aqui mesmo, no Brasil, por um empreendimento insólito - a publicação da tradução de alguns dentre os mais radicais desses poemas numa edição bilíngue, que escapou por pouco de ser a primeira homenagem desse tipo, em escala mundial, ao discutido poeta norte-americano. (p. 29)

Antecipadora, por pouco a primeira: esse é o tom com que os ensaios-prefácios abrem as edições das traduções, destacando como o projeto da poesia concreta sai na frente, mais cedo diz o texto, de outras tradições poético-críticas em termos de reconhecimento do lugar de Cummings em um paideuma modernista. Para que tal reconhecimento ocorresse, para que o presente 
atualizasse o passado reformulando-o, relendo-o a nova luz, a contrapelo, e dando sentido a partir dessa historiografia espacial (constelar, preferem os concretos) era preciso que um projeto como o de poesia concreta surgisse. O conceito é deveras interessante - o de poética sincrônica - mas o discurso autoproclamador do pioneirismo desconstrói a desimportância do início linear - a linhagem, a afiliação pode ser banquete antropofágico, mas em algum momento é preciso mostrar que esse canibalismo é original. Dito de outro modo, essa ideia da cópia regeneradora, de converter a angústia da influência, na feliz acepção de Bloom (2002, p. 92-93), em festim canibal, metáfora-totem da teoria e práxis tradutória de Haroldo de Campos, irmão de Augusto, a guiar e iluminar essa nova tradição tradutória no Brasil, é desmentida por esse retorno fanstasmático da origem: é preciso que a reflexão, a crítica e a tradução sejam inovadoras, pioneiras, melhor equipadas, pela própria devoração que a funda, a lidar com os diferentes materiais, indigestos para tradições teórico-críticas mais conservadores em seu gosto.

Esse tom, contudo, é matizado conforme as edições desta empreitada tradutória se sucedem (somando cinco edições, ao total), ampliando o leque e sacrificando a inovação à representatividade: a última edição contempla 74 poemas, retirados de 12 obras a abranger 40 anos da poética cummingsiana. Podemos dizer que, no final das contas, vence o poeta e, logo, o tradutor, em detrimento do crítico e da programática concretista. Contudo, certa discrepância deve ser considerada: conforme Haroldo de Campos desdobra sua teoria e prática tradutórias, caminhando para erigir a antropofagia como metáfora/ metonímia do seu fazer tradutório/poético, passando de transcriação à transluciferação à plagiotropia, Augusto de Campos parece se recolher em seu vezo crítico e teórico, pelo menos no que tange à obra cummingsiana, privilegiando em sua crítica o craft, a tradução amorosa e artesanal da técnica cummingsiana. Caminham os irmãos na mesma direção em suas práxis? Acreditamos que quando Haroldo se move para uma teoria e uma poiesis mais em consonância ao grito antropofágico, $\mathrm{Au}$ gusto, contudo, não o segue - talvez Cummings seja um dos casos a demonstrar tal divergência - Cummings, esse projeto sempre revisitado, ampliado, revisado.
No ensaio-prefácio que abre a terceira edição de traduções cummingsianas, "30 anos, 40 poemas", Augusto de Campos, inclusive, ressalta a mudança de direção na seleção dos poemas traduzidos:

Aos poemas "tortográficos", privilegiados nas anteriores edições, e acrescidos de outros "hits", incorporaram-se agora alguns textos aparentemente menos atrevidos, mas que evidenciam uma face nada desprezível da rebeldia cummingsiana - o seu humor, a ironia ferina e até feroz com que, incansavelmente fustiga a "manunkind" (humanimaldade). Veja-se um poema como "oDE" [em nota de rodapé: nesta edição, no 9] (de 1926), uma sátira às velhas raposas da política. Ou o poema antibélico "palto told” [em nota de rodapé: nesta edição, no 28] (platão lhe/disse), que se compreende melhor quando se sabe que foi escrito em 1944, pós -Pearl Harbor, e que antes das Segunda Guerra a antiga ferrovia elevada (a "el") de Nova York fora vendida como sucata para os japoneses e, supostamente, usada na fabricação de bombas. $\mathrm{Ou}$, ainda, aquele "when serpents bargain for the right to squirm" [em nota de rodapé: nesta edição, no 35] (quando as serpentes pagam para ser serpentes), que opõe a naturalidade da natureza ao artificialismo do universo convencional e repressivo a que chegou a "humanidade inanimal" (p. 31)

É preciso ter em mente que estamos abordando a terceira edição das traduções de Cummings feitas por Augusto de Campos, publicada em 1986, e que há a ampliação do repertório técnico e temático do poeta estadunidense, abordando, como anteriormente citado, poemas de todas as suas fases, bem como poemas mais próximos da dicção tradicional, opção anteriormente descartada em favor dos poemas mais "criativos". São, portanto, como o prefácio que abre esta edição diz, 30 anos de Cummings no Brasil, circulando a partir das duas edições anteriores que privilegiam, como o próprio tradutor ressalta em seus prefácios, um dos aspectos da poética cummingsiana, o da técnica inovadora e criativa. As outras três edições posteriores irão sedimentar o sucesso dessa longa empreitada tradutória e firmar Augusto de Campos como uma referência incortornável para leitores e estudiosos de Cummings no Brasil, moldando a recepção e circulação do poeta em 
território nacional a partir da agenda do movimento de poesia concreta.

Esta edição, a terceira, é também considerada pelo tradutor como a primeira edição comercial e tem o intuito de atingir um público maior:

As primeiras edições de Cummings no Brasil tiveram limitada tiragem. Existiram à margem. A primeira (acolhida por Simeão Leal, no Ministério da Educação, por sugestão de Oliveira Bastos) já fora uma bravura. A segunda, com a nobre marca da Noa-Noa de Cleber Teixeira, uma loucura. Mas fazia falta uma edição que permitisse um contato maior com o nosso público. É o que almejo para esta nova coletânea, ampliada em poemas e em documentação (cartas e provas corrigidas por Cummings para a primeira edição, que configura, importante subsídio crítico). Felizmente, o NO THANKS dos tempos de incompreensão pode ser hoje convertido no seu oposto. SIM, OBRIGADO. Nós é que o devemos a E. E. Cummings pela aventura de sua poesia. (2011, p. 35)

A primeira edição comercial traz em seu tom a ideia de dever cumprido: o SIM, OBRIGADO foi conquistado a duras penas, após a insistência frente a muitos NO THANKS - ou frente a um sim parcial, para poucos. Ao apontar que um público maior pode agora ler Cummings queda-se implícito o pressuposto de que há, portanto, um público para lê-lo, treinado, inclusive, para apreciar o material extra que a edição traz - os ensaios-prefácios, as provas corrigidas das traduções e as cartas entre os poetas, além do próprio ensaio "Intradução". O corolário deste projeto se condensa na seguinte fórmula: se a crítica é o espaço da reflexão no qual o material literário e poético é expandido, iluminado, aproximado, desdobrado; se a tradução é o locus mesmo da leitura e da interpretação amorosa e devoradora; se ambas implicam uma dimensão ativa e criadora do texto original, não se pode mais pensar na distinção de gêneros entre a crítica, o ensaio, a carta, a tradução e a poesia - são todos poiesis, diríamos, poiesis que se retroalimentam - carne, sangue.

Nas terceira e quarta edições figura na capa a famosa e debatida (in)tradução de " 1 (a", minuciosamente detalhada no ensaio "Intradução de Cummings" (2011), originalmente publicado em 1985. No ensaio, o tradutor ressalta a visada do processo tradutório como equa- ção na qual as perdas devem ser comparadas aos ganhos, em um delicado trabalho de compensação, para avaliar sua validade e/ou valor: “[a] minha 'intradução' tem menos letras - 16 - e mais dois parênteses (...) se Cummings pôde usar menos tintas, com apenas 4 vogais e 4 consoantes, o seu esforçado 'intradutor' conseguiu, pelo menos, equilibrar as ocorrências vocálicas e consonantais" (2011, p. 42). Equilibrar e recuperar são dois verbos que Augusto de Campos irá usar para ressaltar esse trabalho de tradução compensatória. O tradutor também ressalta seu papel/tarefa de iluminar o original, se não em sentido e compreensão em termos de sua técnica e beleza: "[o] resultado, como se vê na reprodução adiante, fica muito aquém do original, mas talvez até contribua, por comparação - e isso o justifica - para realçar lhe a perfeição e demonstrar a excelência dos achados cummingsianos" (p. 42-43). O foco ainda está, como se vê - na capa e na introdução - no olho e fôlego do autor-poeta pelas lentes do poeta-tradutor.

E. E. Cummings - Poem $(a)$ s, por sua vez, possui duas edições: a primeira pela Editora Francisco Alves (1999) e a segunda pela Editora da Unicamp (2011), versão base da qual estamos extraindo os poemas e suas traduções, aqui interpretados. Acrescidos a essa edição, como nos informa sumário posterior ao prefácio da edição de 1999 - "E. E. Cummings, sempre jovem" - estão 11 poemas. ${ }^{11}$ É importante destacar na citação não as linhas temáticas apontadas pelo poetatradutor per se, mas sim as linhas temáticas às quais pertencem os poemas eleitos pelo tradutor, particularmente nas primeiras edições - 10 Poemas, 20 Poem (a)s, 40 Poem (a)s: grande parte, pelo que nosso mapeamento aponta, encontra-se ou na vertente descritiva - e o motivo se torna, à primeira vista, muito claro; afinal, estamos argumentando como o horizonte do tradutor, que encampa tanto sua posição tradutória como seu projeto de tradução, conforma não somente as escolhas linguístico-literárias no material do poemas, mas, também, as escolhas frente à vasta obra do autor - e nos poemas satíricos, que, enfatiza AC, são "a antítese dos poemas amorosos ou encomiásticos", vertente na qual, alega o tradutor "situa-se uma larga porção da poesia de Cummings". Do total de 74 poemas traduzidos para segunda edição de Poem(a)s, 32 são provenientes de suas 
últimas obras - 95 POEMS (1958) e 73 POEMS (1963), sendo 19 da primeira e 13 da segunda, obras estas em que, aponta a crítica mais tradicional, há um recrudescimento das técnicas - isto é, ao invés de "amadurecer" e parar de brincar com suas técnicas tipográficas e sintáticas, o poeta se aferra a elas, retornando aos temas que Augusto de Campos chama de descritivo e satírico. Outro ponto importante levantado pelo tradutor nesse mapeamento das linhas temáticas de Cummings diz respeito ao peso dado à lírica amorosa cummingsiana: mesmo contemplada nas traduções posteriores e apesar de reconhecida como "altamente significativa", merece pouca ou nenhuma menção - alongando-se o poeta, contudo, nas vertentes já citadas. ${ }^{12}$

Vimos, ao longo do texto, articulando a prática tradutória e crítica de Augusto de Campos de modo a iluminar seu horizonte tradutório, isto é, a chamar a atenção para de que modo seu projeto de tradução e sua posição tradutória (isto é, suas crenças acerca do papel da tradução e do tradutor e das relações que estes travam com o texto fonte e o autor), bem como sua agenda de tradução, pautada pelo movimento de poesia concreta, conformam sua leitura ${ }^{13}$ da obra de Cummings, e, logo, impactam na formação de um cânone brasileiro da obra cummingsiana centrado em um corpus composto por amostras escolhidas de sua técnica. Se repensarmos a problemática posta pela tradução para Cummings e seu tradutor, Augusto de Campos, perceberemos que Campos caminha entre um modelo de tradução, por vezes literal, mas embasado nos preceitos de tradução livre e criativa, ou seja, da dita transcriação: o aspecto formal/visual, como já foi apontando, é preponderante nas escolhas tradutórias de Augusto de Campos, seja dos exemplares a serem traduzidos, seja das escolhas tradutórias no corpo do poema-tradução. Vimos ao longo do texto como essas escolhas impactaram no projeto tradutório do poeta-tradutor e, logo, na conformação de um cânone brasileiro da poesia de Cummings, isto é, na circulação e recepção do texto do poeta estadunidense.

Essas escolhas impactam também na própria técnica da tradução e no que ela ilumina ou oblitera quando se passa aos poemas líricos. O poema no. 4 é um dos favoritos entre os leitores de Cummings, recorren- temente reproduzido e antologizado. Contudo, é interessante que ele só venha a ser traduzido por Augusto de Campos na edição de 2011, assim como o poema n. 12, "since feeling is first". Ambos são provenientes de obras da década de 20, o primeiro de $\triangleleft A N D$ (1925) e o segundo de IS 5 (1926) e ilustram outro dos grandes temas cummingsianos, aliás, o grande tema - o amor. $\mathrm{O}$ recorte do tradutor para as obras anteriores privilegiava e se punha em função do retrato do artista às margens do mainstream: à rebeldia de ordem formal tipográfica, espacial etc - soma-se a rebeldia de ordem temática: às traduções anteriores agregam-se traduções do Cummings mais político e filosófico, a tecer observações sobre o mundo e suas conformações a cercear o homem em sua tendência para a liberdade, fossem elas de ordem política, amorosa ou artística. Contudo, é apenas nas últimas edições, com exceção de "somewhere i have never travelled, gladly beyond", anteriormente traduzido, que essa vertente amoroso-lírica é incorporada às traduções, uma resistência que aponta para o projeto tradutório de Campos e sua adesão ao programa do movimento de poesia concreta, que se propunha a extinguir a praga liricizante do Romantismo, corpo em decomposição a ser arrastado por poetas-necrófilos - essa é a tônica do discurso, poundiano, por sinal. Podemos inferir que somente quando a questão programática do movimento de poesia concreta se dilui afinal, na década de 60 ele se desmembra e se propõe outros caminhos - é que o tradutor se permite (talvez por um acerto de contas com a poética cummingsiana ou, ainda, pela influência de Paz (1976), esse outro leitor-tradutor de Cummings) acercar-se deste que, segundo Paz (1976), é o tema articulador da poética cummingsiana ${ }^{14}$ : tu e eu. Os poemas desta vertente articulam-se a partir do eterno movimento entre união e separação, contração e relaxamento - diástole e sístole, dessa união primordial entre homem/ mulher, natureza. O movimento, de afastamento ou de junção é o objeto de escrutínio e de trabalho para o poeta: quando há a junção, aproximação, fala-se de amor, dessa conjunção de signos, como nos aponta Paz (1976): afinal, "[h]á um ponto de convergência entre os enamorados e o mundo: o poema". O poema, contudo, pode dizer da divergência: e o humor ferino de Cummings bem nos 
mostra como o poeta reage à disjunção/descompasso entre a humanidade (humanimaldade/humanidade inanimal) e a natureza. Analisemos, agora, o poema no $4 i$ like my body when it is with your.

Em "i like my body when it is with your" temos o poeta a brincar com a forma soneto: a forma é mantida, mas o pentâmetro iâmbico vem com o pé quebrado - a pontuação, inclusive, reforça o enjambement dos versos. $\mathrm{O}$ pentâmetro iâmbico, típico do soneto inglês, vem para a língua portuguesa como alexandrino também quebrado: eu gosto do meu corpo / quando está com o seu /corpo há o ponto de cesura, mas o enjambement de "corpo" no verso subsequente quebra a métrica, que irá se alternar em decassílabos e dodecassílabos, como o próprio movimento do corpo que se expande e se contrai - músculos, nervos, vértebras. E esse é outro aspecto do soneto cummingsiano: seu tema não é o amor idealizado e incorpóreo em que a amada é descrita como rosa-anjo, etérea e evanescente e, por isso, intocável. O amor, em Cummings, é sempre corpo e anima: o corpo, aliás, desempenha papel central na lírica amorosa cummingsiana, pela lógica própria, resistente à racionalização e ao abstrato; o corpo, portanto, é este aqui-agora-em-movimento que a poiesis cummingsiana tanto reverencia, é o ponto de convergência entre o tu e o eu, momento em que a poética corporal e a erótica verbal (fórmula consagrada por Paz (1994) em A dupla chama para destacar a afinidade entre erotismo e poesia) se condensam, momento de alteridade em que o eu se constitui a partir do tu:

i like my body when it is with your body. It is so quite new a thing.

eu gosto do meu corpo quando está com o seu corpo. É uma coisa tão nova e viva.

(2011, p. 56-57)

A ênfase nos possessivos meu corpo/seu corpo, nessa distinção, é ao mesmo tempo reforçada e apagada: eu gosto do meu corpo quando está com o seu corpo - é a partir do seu corpo que o meu se (res)significa, torna-se signo, pode ser lido, torna-se, na sintaxe, "so quite new a thing". A transgressão da sintaxe operada nesse segundo verso, apesar de tímida se comparada aos padrões cum- mingsianos, é, de certa forma, perdida quando vertida para o português "É uma coisa tão nova e viva". O uso de "tão", que traduz bem so, não consegue traduzir a hesitação entre os dois advérbios so e quite, sendo o primeiro pronunciadamente mais enfático que o segundo, a qualificar o adjetivo new que pede como complemento o substantivo, negado pela intervenção do artigo indefinido $a$, a reforçar a indefinição já apontada em thing/ coisa: "uma coisa tão nova e viva". Augusto de Campos, contudo, acresce à tradução o adjetivo "viva", "nova e viva", opção que manterá quando, ao final do poema, no clímax, houver a repetição: "you so quite new"/ "tão viva e nova assim", traduzindo so não mais como advérbio de intensidade (tão) mas de modo: assim. Se examinarmos mais detidamente os dois poemas, perceberemos que em língua portuguesa há, na descrição do ato amoroso em curso, certa suavização:
[...] i will again and again and again kiss, i like kissing this and that of you, i like, slowly stroking the,shocking fuzz of your electric fur,and what-is-it comes over parting flesh....And eyes big love-crumbs,
and possibly i like the thrill
of under me you so quite new

\begin{abstract}
mais e mais e mais
beijar, gosto de beijar issoeaquilo de você, gosto de,lentamente golpeando o,choque do seu velo elétrico,e o-que-quer-que freme sobre a carne bipartida....E olhos migalhas

de amor grandes e acho que gosto de ver sob mim você vibrar tão viva e nova assim (2011, p. 56-57)
\end{abstract}

Notamos que há uma intensificação/exasperação do desejo, demonstrado pela sequência de repetições - "again and again and again" interpostos à oração afirmativa ao " $i$ will kiss". Again poderia ter sido traduzido como "novamente" ou "de novo", mas Augusto de Campos, talvez para evitar o eco - afinal, "novo" como adjetivo é usado, com flexão de gênero, no primeiro e último versos - opta pelo advérbio "mais", satisfatório para indi- 
car esse frêmito do desejo - "mais e mais e mais". Contudo, a oração principal, em língua portuguesa, perde a força que a afirmação em língua inglesa confere: " $i$ will kiss" é traduzido como "eu quero beijar". Apesar do desejo ser ressaltado no verbo "querer", há um arrefecimento na certeza que o verbo modal "will" confere ao verbo "kiss": "eu quero beijar" diz do desejo do enunciador; " $i$ will kiss" diz de sua postura frente a esse desejo - eu irei beijar/beijarei/vou beijar . Na sequência, contudo, "i like kissing this and that of you", podemos perceber que o tradutor propõe certa compensação por essa perda em termos de ação: o trecho é traduzido como "gosto de beijar issoeaquilo de você", semanticamente muito próximo ao poema-fonte, com uma emulação de um recurso cummingsiano, a junção de termos de modo a cunhar um novo substantivo "issoeaquilo", como se a boca que beija não se afastasse ou do corpo beijado, minuciosamente percorrido. Esse recurso, aliás, enfatizando essa conjunção entre corpo/corpo, meu/seu, aliás, é empregado nos próximos versos por Cummings:

i like, slowly stroking the,shocking fuzz of your electric fur,and what-is-it comes over parting flesh.... And eyes big love-crumbs,

gosto de, lentamente golpeando o, choque do seu velo elétrico,e o-que-quer-que freme sobre a carne bipartida....E olhos migalhas (2011, p. 56-57)

A intensificação, o frêmito, essa aproximação é indicada pelos sentenças-versos que não somente, via enjambement, vão se encaixando umas as outras, em uma espécie de aceleração do ritmo, do fôlego, mas pelo não espaçamento entre vírgulas e texto: tudo flui em contínuo movimento até o "what-is-it comes over parting flesh...", a terminar nas reticências - indicando o que não pode ser dito pela própria dissolução do discurso naquele momento: não mais tu e eu, mas nós. Neste trecho, particularmente, algumas escolhas de tradução nos intrigam: primeiro, no décimo verso, perde-se a aliteração com as fricativas "slowly stroking the,shocking fuzz" em uma tradução que não privilegia a exatidão semântica - "golpeando", em língua portuguesa, carrega uma carga semântica relativa à agressivi- dade que stroking não possui, podendo o termo ter sido traduzindo por acariciando, ou alisando - indicando movimento lento e contínuo. O jogo entre fuzz/fur é também perdido: fuzz não é contemplado na tradução, sendo o sintagma shocking fuzz traduzido por choque que, recategorizado, passou de adjetivo a substantivo; fur, por sua vez, é traduzido como velo - uma das possibilidades, entre outras como pelúcia ou mesmo pele - termo que em língua portuguesa, contudo, é pouco familiar ao leitor comum, ao contexto do dia a dia, ao contrário de fur, termo do dia a dia, comum, em língua inglesa. O duplo reforço dos adjetivos shocking/electric não é, também, contemplado. A continuação do verso, separado por vírgulas mas não pelos convencionais espalhamentos, também apresenta outro problema: "and what-is-it comes" é traduzido como "e o-que-quer-que freme"; "freme" por "comes" aponta, novamente, uma escolha vocabular por parte do tradutor que não é respaldada pelo poema-fonte: to come, como se sabe, é, também, gozar em língua inglesa- chegar lá, termo coloquial; freme, por sua vez, assim como velo, soa a poesia parnasiana, como se o tema em questão, o objeto do poema precisasse ser (re)coberto por um vocabulário preciosista, mais formal, menos afim ao dia a dia. Como efeito geral, há uma solenização do ato em língua portuguesa; no poema de Cummings, essa solenização não é atingida por meio da escolha vocabular - não solenização, mas sagração/santificação, visto que a união na concepção (meta)física do poeta é sempre o reencenamento daquela união pagã sem culpa, hieros gamos, a união sagrada - mas pelo olhar enamorado:

\section{[...] And eyes big love-crumbs, and possibly $i$ like the thrill of under me you so quite new}

[...] ....E olhos migalhas de amor grandes e acho que gosto de ver sob $\operatorname{mim}$ você vibrar tão viva e nova assim (2011, p. 56-57)

No decorrer deste texto discutimos algumas das questões relativas ao processo tradutório de modo a compreender tanto o perfil tradutório de Augusto de 
Campos, bem como seu projeto - crítico, teórico e pedagógico - que acabou por fundar, juntamente a seu irmão Haroldo, uma outra tradição brasileira de tradução. Notamos também que a problemática central no que tange à tradução, apontada pela literatura, em particular pela poesia, e, mais especificamente ainda pela obra de Cummings, centra-se no ponto de resistência das questões de traduzibilidade. A partir do conceito de tradução dos irmãos Campos, a transcriação, discutimos a tradução criativa, afim às propostas de Meschonnic (2009) e Berman (2007) que concebem a prática tradutória como literária, não ciência ou teoria, mas craft, experiência, reflexão, fazer - ressaltando, portanto, a informação de ordem estética como a privilegiada nas escolhas de tradução de poema. Nessa perspectiva, subjaz uma teoria da linguagem que está como fundo do movimento de poesia concreta, uma teoria em que a semântica desloca-se do verso, da frase, da ordem discursiva e abrange o espaço em branco no texto, espaço para a construção do poema-palavra ou da palavrapoema, ferramenta, ícone e objeto, não valise a transportar - e quiçá derrubar, no meio do caminho, por descuido, talvez - os preciosos significados, guardados sob camadas e véus.

Parte de nosso trabalho estava em apontar como as escolhas feitas por Augusto de Campos em termos de corpus para tradução e dos procedimentos e estratégias de tradução ao realizar a transcriação dos poemas de Cummings integravam seu horizonte tradutório, conformado pela pauta do movimento de poesia concreta que, via tradução e crítica, forjava um cânone doméstico de autores estrangeiros diversos, de modo a validar sua proposta poética. Por fim, analisamos como Augusto de Campos trabalhou no texto-tradução a informação poética que compõe o texto-poema e suas escolhas de modo a ressaltar aspectos semânticos, plásticos $\mathrm{e}$ sonoros, particularmente quando este poema figurava como um dos exemplares da técnica cummingsiana. Contudo, pelo que se pode observar ao longo das traduções aqui analisadas, o tradutor dispensa tratamento diferenciado à obra cummingsiana, privilegiando certos poemas que ilustram de modo mais conspícuo a questão da intraduzibilidade da informação estética, isto é, em que questões como tipografia e quebras sintáticas e morfológicas estão mais evidenciadas. Estas escolhas, portanto, revelam que o projeto, posição e horizonte tradutórios do poeta-tradutor foram pautados pelo programa do movimento de poesia concreta, o que acabou por afetar não somente o recorte da obra cummingsiana oferecida ao público brasileiro, mas, também, a relevância dada a sua lírica-amorosa e, logo, a representação e compreensão de Cummings e de sua obra no contexto brasileiro.

\section{Notas}

1. Campos retoma essa memória da recepção cummingsina pelos críticos contemparâneos ao poeta em seu ensaio NÃO, OBRIGADO, introdução à edição de E. E. Cummings - 20 poemas. Vide a edição ampliada de 2011, p. 27. Ele cita particularmente os novos críticos, representantes da corrente crítica denominada New Criticism, e elencando dentre estes F.O. Matthiessen (Review of 1 X 1, Kenyon Review, 1944, p. 77-78), Yvor Winters (Merely a Penumbra, American Literature, 1939, p. 98-99.), Philip Horton e Sherry Mangan (1938), dentre outros. HORTON, Philip and Sherry Mangan ( Two Views of Cummings, Partisan Review, 1938).

2. Tmese, segundo Augusto de Campos, significa secção, corte, operação na qual prefixos e sufixos são dispersos e rearranjados ao modo do latim e do grego, conforme nos informa em seu ensaio-prefácio "E. E. Cummings, sempre jovem” (CAMPOS, 2011, p.13).

3. Paideuma, conceito derivado de Pound, trata da seleção de escritores-criadores que têm função pedagógica de ensinar aos leitores e aos poetas como ler / escrever a partir do que se tem de melhor em termos de uma dita tradição literária de ruptura, de inovação.

4. Segue a introdução de Cummings a IS 5, que também está em Poem(a)s: "Na presunção de que minha técnica seja complicada ou original, ou ambas, os editores me solicitaram cortesmente que escrevesse uma introdução para este livro. Ao menos, a minha teoria da técnica, se é que tenho alguma, está muito longe de ser original, nem é uma teoria complicada. Posso exprimi-la em quinze palavras citando A Eterna Pergunta e Imortal Resposta do teatro burlesco, i. é: "Você bateria em uma mulher com uma criança? - Não, eu lhe bateria com um tijolo". Como o comediante burlesco, sou extraordinariamente apegado àquela precisão que cria o movimento. Se o poeta é alguém, ele é alguém para quem as coisas feitas importam muito pouco - alguém que é obcecado pelo Fazer. Como todas as obsessões, a obsessão de Fazer tem suas desvantagens; por exemplo, meu único interesse em fazer dinheiro seria 
fazê-lo. Mas felizmente eu preferiria fazer quase tudo o mais, inclusive locomotivas e rosas. É com rosas e locomotivas (para não mencionar acrobatas primavera eletricidade Coney Island o 4 de Julho os olhos dos camundongos e as Cataratas do Niágara) que meus "poemas" competem. Eles também competem uns com os outros, com elefantes e com El Greco. A inelutável preocupação com $\mathrm{O}$ Verbo dá ao poeta uma vantagem sem preço: enquanto os nãofazedores devem contentarse com o fato simplesmente irrecusável de que dois e dois são quatro, ele se compraz com uma verdade puramente irresistível (a ser encontrada, de forma sintética, no título deste volume)" (CUMMINGS/ CAMPOS, 2011, p. 49).

5. Todas as referências às obras de E. E. Cummings foram retiradas da edição comemorativa dos seus cem anos de nascimento, editada por George G. Firmage e publicada em 1994 pela Liveright: E. E. Cummings complete poems 1904-1962: revised, corrected, and expanded edition containing all the published poetry.

6. Para traçar essa narrativa da tradução brasileira de Cummings em oposição à recepção do poeta e tradução em solo norte-americano e espanhol, consultar os prefácios das edições, aqui elencados em ordem: "E. E. Cummings, olho \& fôlego", "Não, obrigado", "30 anos, 40 poemas" e "Intradução de Cummings". Todos estes textos foram consultados a partir da edição revista e ampliada de 2011 - Poem (a)s.

7. Assim relata o poeta-tradutor: "As minhas primeiras traduções da poesia de Cummings, reunidas em livro em 1960 (E. E. Cummings - 10 poemas, edição do Ministério da Cultura), enfatizaram o poeta das experiências de gestualização tipográfica, o mais revolucionário e o menos aceito e entendido. Delineado o perfil do poeta-inventor e implodida a textura tradicional do poema com a exposição dessa inusitada "tortografia", tornou-se possível explorar, em leituras posteriores, o espectro mais amplo das vertentes cummingsianas. Duas novas seleções de poemas, publicadas em 1979 (E. E. Cummings - 20 poem(a)s, Editora Noa Noa) e 1986 (E. E. Cummings - 40 poem(a)s, Editora Brasiliense), ampliaram o número de textos traduzidos, enfatizando o humor cummingsiano e as sutilezas de sua fase derradeira. Nesta nova edição, comemorativa do centenário do nascimento do poeta, pretendo homenageá-lo com mais 22 traduções, abrangendo todas as suas faces e estilos. Das composições líricas da juventude como "somewhere i have never travelled" (nalgum lugar em que eu nunca estive) - no 15 - aos poemas objetivistas, como os que tematizam a mosca, a lua, o floco de neve, a estrela, a camponesa. Dos epigramas críticoanedóticos, como os de no 51 e no 52, que descrevem os bêbados de rua - "a he as o" (um o tão v), "a gr" (um bê) -, aos poemas francamente satíricos, como o antibelicista "why must itself up every of a park" (por que haverá em cada de um parque), no 37, ou os que escarnecem os "unpeople", as nãopessoas, sem horizonte a não ser a vida prática e o lucro, como o de no 50, "shat Got him was Noth" (o que o Levou não foi o Nad) ou o de no 56, "you no" (você re)" (2011, p. 16-17)

8. Segundo AC, "Cummings atua diretamente sobre a palavra, desintegra-a, cria com suas articulações e desarticulações uma verdadeira dialética de olho e fôlego, que faz do poema um objeto sensível, quase palpável. (...) $\mathrm{Na}$ poesia de Cummings as palavras não são dissociadas de seu significado, nem as letras valem por si sós. A atomização dos vocábulos tem em mira efeitos construtivos de sinestesia do movimento e fisiognomia descritiva. Sob a aparência epidérmica de idiossincrasia e anarquismo, a tortografia cummingsiana é, paradoxalmente, a correção de uma ortografia inane para a poesia, de uma mortografia, ao mesmo tempo que uma das mais sérias tentativas de fazer funcionar dinamicamente o instrumento verbal, reduzindo a um mínimo - como nota Theodore Spencer - a distância entre experiência e expressão. Estrutura orgânica, expressionismo vocabular (gesticulação tipográfica), desfiguração (nem sempre superação) do discursivo, são características da poesia espacial de E. E. Cummings, que poderia encontrar, no plano das artes visuais, o seu melhor equivalente em Paul Klee" (2011, p. 25)

9. Contudo, outra associação imediata com a qual esse soneto conta parte de direção totalmente contrária, muito no estilo cummingsiano de pôr em circulação referências da cultura popular e da cultura erudita, seria o soneto modelo Bright Star, de John Keats, o grande poeta do romantismo inglês, com seu preciosismo e mesmo arcaísmo terminológico. Essa associação/ evocação acaba por se perder na versão em língua portuguesa. Perceba-se que a evocação do soneto de Keats se dá de modo paradigmático: é o sintagma "bright star" (que no texto brinca de esconde-esconde com o leitor, até aparecer inteiro) que evoca, pelo título, o soneto Bright Star (ABRAMS, 1999, p. 845). O jogo de Cummings, contudo, vai além: o adjetivo usado para qualificar a estrela no soneto de Keats, já presente no título, destaca sua luminescência, sua radiância (bright); o segundo, contudo, na primeira estrofe do soneto de Keats, é steadfast - constante (ou imóvel). À essa constância da estrela keatsina opõese à luminescência inconstante, twinkling, da estrela cummingsiana. Steadfast é retomado, posteriormente, ao longo do poema de Keats, por unchangeable/ imutável. A estrela de Cummings, com seu brilho fugidio, é, antes de tudo, mutável: o poeta americano privilegia seu movimento e pela sua escrita tenta 
capturá-lo, concordando, contudo, com o aspecto sagrado dessa estrela que, holy alone/whole alone - só - mas sem desespero (calma), queda-se a observar e ser observada.

10. Trecho da Introdução de 20 poem $(a) s:$ "Mais de 20 anos depois, Cleber Teixeira, poeta-tipógrafo-editorvisionário, me propõe reencetar a aventura. Pago a sua coragem com mais dez poemas. Alguém nos ouvirá? Não importa. Com E. E. Cummings dedicamos esta edição aos “não, obrigado". E à memória de um homem 'que não tinha renda, porque não estava à venda"' (2011, p. 32).

11. Os 11 poemas acrescidos à última edição de Poem $(a) s$ são: o no 2 the Cambridge ladies who live in furnished souls (as damas de Cambridge que moram em almas mobiliadas), de TULIPS AND CHIMNEYS (1923); o no 4 i like my body (eu gosto do meu corpo), de \&AND (1925); no 6 Buffalo Bill's (Bufallo Bill é), de XLI POEMS (1925); no 7 POEM,OR BEAUTY HURTS MR. VINAL (POEMA,OU A BELEZA FERE O SR. VINAL), no 11 "next too $f$ course god america $i$ ("depois de é claro deus américa eu) e no 12 since feeling is first (já que sentir vem antes), de de IS 5 (1926); no 32 how (tão), de 1 X 1 (ONE TIMES ONE) (1944); no 34 chas sing does(who (chas sing não ca(e ), de XAIPE (1950); no 46 joys faces friends (alegrias faces amigos), no 47 why from this her and him (por que deste ela e ele) e no 59 out of the lie of no (da mentira do não), de 95 POEMS (1958), sua última obra publicada em vida.

12. A respeito das escolhas tradutórias, o poetatradutor, após elencar as edições prévias apontando as escolhas feitas, destaca o seguinte: "Nesta nova edição, comemorativa do centenário do nascimento do poeta, pretendo homenageá-lo com mais 22 traduções, abrangendo todas as suas faces e estilos. Das composições líricas de juventude como "somewhere i have never travelled" (nalgum lugar em que eu nunca estive) - no 15 - aos poemas objetivistas, como os que tematizam a mosca, a lua, o floco de neve, a estrela, a camponesa. Dos epigramas crítico-anedóticos, como os de no 51 e no 52, que descrevem os bêbados de rua - "a he as o" (um o tão v", "a gr" (um bê) -, aos poemas francamente satíricos, como o antibelicista "why must itself up every park" (por que haverá de em cada de um parque), no 37, ou os que escarnecem os "unpeople", as nãopessoas, sem horizonte a não ser a vida prática e o lucro, como o de no 50, "what Got him was Noth" (o que o Levou não foi Nad) ou o de no 56, "you no” (você re)." (CAMPOS, A; 2011, p. 17)

13. É sempre bom ter em mente que o exercício da tradução é, primeiro, exercício da leitura e da intepretação - o tradutor, a princípio, é o leitor ideal, particularmente de poesia, pois tem no signo e suas faces - significado e significante - seu ponto focal.
14. Segundo Paz (1976), em Signos em rotação, "Os poemas de cummings são filhos do cálculo a serviço da paixão. Observa-se que, tanto na vida como na arte, a paixão, para satisfazer-se, demanda um máximo de artifício e não se contenta, jamais, com a realidade se não a transmutar, antes, em símbolo? O erotismo tende à cerimônia; o amor é emblemático; a curiosidade se exalta face aos enigmas, simultaneamente jogo infantil e rito de passagem entre os antigos. Adivinhações, erotismo, amor: sistemas de correspondência, linguagem em que não apenas os objetos, as cores e os sons mas também os corpos e almas são símbolos. Vivemos em um mundo de signos. Todas as imagens de cummings podem ser reduzidas às combinações destes dois signos: tu e eu. O resto dos pronomes são obstáculos ou estímulos, muros ou portas. Entre eu e tu a relação é a conjunção copulativa/aditiva ou adversativa. O mundo é uma analogia do casal primordial e suas trocas refletem as trocas do tu e do eu em suas uniões e separações. Esse tu e eu, genérico embora não impessoal, é o personagem único de uma grande parte da poesia de cummings. É o casal de enamorados, sós na sociedade dos maiores, mas em constante comunicação com o mundo das árvores, das nuvens, da chuva. O mundo é seu talismã e eles são os talismãs do mundo. Entre o mundo e os pronomes se interpõem as instituições, as barbas dos velhos, as estolas das velhas, as bombas dos generais, os bancos, os programas de redenção do gênero humano. Há um ponto de convergência entre os enamorados e o mundo: o poema. Ali, as árvores se abraçam, a chuva se desnuda, a moça reverdesce, o amor é um raio, a cama uma barca. O poema é emblema da linguagem da natureza e dos corpos. O coração desse emblema é o verbo: a palavra em movimento, o motor e o espírito da frase. Conjugação dos corpos, copulação dos astros: a linguagem resolve todas as oposições na ação metafórica do verbo. A sintaxe é uma analogia do mundo e dos enamorados." (PAZ, 1976, p. 232).

\section{Referências}

ABRAMS, Meyer Howard. (Ed.).The Northon anthology of English literature: the romantic period. New York/ London: Norton, 1999. (vol. 2 A)

AGUILAR, Gonzalo. Poesia concreta brasileira: as vanguardas na encruzilhada modernista. São Paulo: EDUSP, 2005.

BERMAN, Antoine. A tradução e a letra, ou O albergue do longínquo. Rio de Janeiro: 7Letras/PGET, 2007.

BLOOM, Harold. A angústia da influência: uma teoria da poesia. 2. ed. Rio de Janeiro: Imago, 2002. 206 p. 
CAMPOS, Augusto de; CAMPOS, Haroldo de. "POESIA CONCRETA- Interview”. Código 11 - Edição Comemorativa dos 30 anos da poesia concreta (1986): sem paginação.

CAMPOS, Haroldo de. Metalinguagem \& outras metas: ensaios de teoria e crítica literária. 4. ed. São Paulo: Perspectiva, 2006. (Debates; 247). p. 231-256.

CAMPOS, Haroldo de. "Post-scriptum: Transluciferação mefistofáustica". In: Deus e o diabo no Fausto de Goethe. São Paulo: Perspectiva, 1981. p. 179-209.

CAMPOS, Haroldo; CAMPOS, Augusto de; PIGNATARI, Décio. Teoria da Poesia Concreta - textos críticos e manifestos. São Paulo: Duas Cidades, 1975.

CUMMINGS, Edward Estlin. Poema(s). Tradução de Augusto de Campos. $2^{\text {a }}$ edição,revista e ampliada. Campinas: Editora da UNICAMP, 2011.

DELEUZE, Gilles; GUATTARI, Felix. Kafka: por uma literatura menor. Rio de Janeiro: Imago, 1977.

FIRMAGE, George G. E. E. Cummings complete poems 1904-1962: revised, corrected, and expanded edition containing all the published poetry. New York: Liveright, 1994.

MESCHONNIC, Henri. Poética do traduzir. 2009. Belo Horizonte: FALE/UFMG, 2009. Disponível em: $<$ http://150.164.100.248/vivavoz/data1/arquivos/poeticadotraduzir-site.pdf> . Acesso em: 15 ago. 2015.

PAZ, Octavio. Signos em Rotação. Tradução de Sebastião Uchoa Leite. São Paulo: Editora Perspectiva, 1976.

. A dupla chama: amor e erotismo. São Paulo: Siciliano, 1994.

PEREIRA, Cristina Monteiro de Castro. Entrevista com Augusto de Campos, Revista Brasileira de Literatura Comparada, n.19, 2011, p. 13-23.

SANTOS, Andréa Soares. O Cânone via tradução: dos concretos aos contemporâneos (Tese). 2010. Universidade Federal de Minas Gerais/ FALE, Belo Horizonte. $286 f$

VENUTI, Lawrence. Escândalos da tradução. São Paulo: EDUSP, 2002.

Recebido em: 15/09/2015

Aceito em: 30/10/2015 